\title{
RELIQUIAS Y ESCOMBROS DEL FUTURO
}

\author{
Raquel Meyers \\ Investigadora independiente
}

\section{Resumen}

Los monumentos se usan como reliquias del futuro para validar y preservar una identidad. La era digital ha dado paso a la era de las tinieblas, en la que monumentos conmemorativos ya no se construyen fisicamente sino únicamente sus narrativas. El sistema educativo STEAM es uno de estos monumentos, que incluye la disciplina del arte, no por su capacidad crítica ni por su sensibilidad; sino por su flexibilidad para fagocitarse a la lógica económica. El futuro no nos necesita. La naturaleza humana se ha convertido en una apuesta económica cuyo destino es convertirse en escombro de Antropoceno. En nuestra manos está aprovechar el tiempo que se nos ha dado. No caben más excusas. Aún podemos resistirnos.

Palabras clave: STEAM; ARTE; FUTURO; TECNOLOGÍA; ESCOMBRO

\section{RELICS AND RUBBLE OF THE FUTURE}

Abstract

Monuments are used as relics of the future to validate and preserve an identity. The digital age has given way to the Dark Enlightenment, in which commemorative monuments are no longer physically constructed but only their narratives. The STEAM educational system is one of these monuments, which includes the discipline of art, not for its critical capacity or sensitivity; but for its flexibility to engulf economic logic. The future does not need us. Human nature has become an economic gamble whose destiny is to become Anthropocene rubble. It is in our hands to take advantage of the time we have been given. There are no more excuses. We can still resist.

Keywords: STEAM; ART; FUTURE; TECHNOLOGY; RUBBLE

\footnotetext{
Meyers, Raquel. 2020. "Reliquias y escombros del futuro". AusArt 8 (1): 283-293. DOI: 10.1387/ausart.21517
}

\section{AUSART}




\section{INTRODUCCIÓN}

Los monumentos se usan como reliquias del futuro para validar y preservar una identidad. Utilizando la hipótesis de que el sistema educativo STEAM (ciencia, tecnología, ingeniería, artes y matemáticas) funciona como un monumento / reliquia y, usando como soporte los conceptos del 'valor de la ruina' ('Ruinwert' en alemán), 'Dark Enlightenment', 'Techno-Totalitarian Reich' (ambos propuestos por "Bifo" Berardi); 'escombro de Antropoceno' y 'murmullo'; propongo la reflexión crítica de que la inclusión del arte en el combo STEM parece funcionar más como un aliño a la receta computacional que justifica la intrusión del valor económico en la sensibilidad humana. En mi opinión, solo confirma la fagocitación del arte a la certeza científica, matemática y económica. El abuso de las palabras ha llevado a los artistas hacia la seguridad de las ciencias, de tal forma que la falta de significado parece paliarse con pseudo procesos científicos que legitimizan y confirman la nueva era de las tinieblas (New Dark Age) como un mero añadido estético producto de la narrativa económica.

\section{STEAM 0 LA RUINWERT ACELERADA}

El término STEM (CTIM en español) se empezó a utilizar en la década de 1990 para potenciar un nuevo tipo de sistema educativo basado en la ciencia, la tecnología, la ingeniería, y las matemáticas. En el año 2006, la iniciativa de Georgette Yakman añadió el arte (Art) al acrónimo, convirtiéndolo en STEAM.

En mi opinión la inclusión del arte en este combo educativo no es más que una estetización de un sistema cuyo propósito final es económico, ya que busca una educación que refuerce la lógica del capital. No debemos olvidar que este sistema se creó en la sociedad capitalista por excelencia Estados Unidos y, como bien Shaviro (2017) nos avisa, "en el capitalismo actual todo es estetizado". STEAM quiere convertirse en el referente, en el monumento educativo que guiará a las futuras generaciones. Como cualquier otro monumento, puede convertirse en una ruina.

El valor de la ruina, 'Ruinwert' en alemán, es un concepto creado por el arquitecto alemán Albert Speer que fue publicado en Die Ruinenwerttheorie en 1936. En él se describe como los edificios deberían ser diseñados para dejar 
ruinas estetizadas. Monumentos para la posteridad. Símbolos que, como describe Bruce Sterling en su artículo, The fascist theory of ruin value (2009), fueron creados para la vanagloria del tercer Reich. Más allá de su connotación fascista, el valor de la ruina sigue vigente como 'mistificación folclórica' (Avanessian 2017), ya no solo sólo del pasado sino de la tecnología.

No debemos olvidar que vivimos en la era digital y que nuestras vidas están condicionadas y controladas por la tecnología. En el estado de alarma que nos ha tocado vivir por la situación generada por la Covid-19, el Big Data se ha convertido en una herramienta que nos confirma, una vez más; un nuevo régimen, el 'Techno-Totalitarian Reich' acotado por "Bifo" Berardi (2019). La tecnología nos ofrece la salvación, claro que solo una vez que hayamos aceptado sus condiciones de uso. Un conjunto de instrucciones y recetas que prometen imparcialidad y puro raciocinio, fácil de usar y con un coste mínimo de libertades, emoticono cara sonriente con la boca abierta. El algoritmo se ha convertido en la piedra filosofal de nuestra era y está rodeado de un misticismo propio de tiempos más oscuros. "Por mucho que los códigos informáticos puedan ser magia y los hackers sus chamanes, los seguiremos identificando como un sistema simbólico que opera en la intersección entre cognición y realidad", argumenta Finn (2018). Estamos inmersos en una teocracia computacional desde hace mucho tiempo y, las circunstancias actuales solamente lo confirman.

Lo que nos espera es una versión tecno-medieval donde todo el conocimiento almacenado quedará reducido a un acceso premium o simplemente desaparecerá dejándonos la nube (the cloud) en ruinas. Internet está destinado al colapso pero su legado se convertirá en una versión estetizada para la contemplación, un Ruinenwert en toda regla. "Hemos aceptado de manera paulatina que el arbitraje de la información es más significativo que la información en sí misma [...] Para muchos de nosotros, toda pregunta imaginable sobre nuestras vidas arranca con una consulta en un buscador, o en otra clase de base de datos algorítmica, y esta nueva legibilidad cambiará nuestra relación con la realidad de una manera tan profunda como epistemológica", reflexiona Finn (2018). No todo va ir bien mientras tengamos conexión a internet y estemos online.

La ruina se acelera cada vez más. Este aceleramiento ha provocado varias voces y movimientos como el Manifiesto para una política aceleracionista de Alex Williams y Nick Srnicek lanzado en 2013. Ambos autores nos alertaban de que "vivimos en una época en la que lo único que se desarrolla es un 
conjunto de aparatos [gadgetry] dirigidos al consumo ligeramente mejorados. Incesantes repeticiones del mismo producto de base sostienen la demanda marginal de consumo a expensas de la aceleración humana". La postura aceleracionista tampoco nos va a sacar del aprieto, el capitalismo es capaz de beneficiarse de cualquier cataclismo y no se va a autodestruir porque se acelere hasta la extenuación. La racionalidad del algoritmo comprende una 'brutalidad contenida' y salvaje, como argumenta Brassier (2017). Un nuevo misticismo cuyo alcance aún no somos capaces de comprender y valorar pero cuyas consecuencias empiezan a ser difíciles de ignorar por mucho que nos empeñemos. "Los hombres siempre tienen teorías, y las cosas han de acomodarse a esas teorías", nos dice Le Guin (1974) en su distopía anarquista Los desposeídos. Para Le Guin el verdadero viaje es el retorno. En mi opinión no es retorno a lo ya conocido ya que aún seguimos de viaje y nos queda mucho por hacer y aprender. Nos hemos resignado a cambio de ciertas comodidades, aceptando y normalizando ese ruido de fondo decorativo de un futuro ya arcaico sin haberse proclamado, una ruinwert acelerada.

\section{LA NUEVA ERA DE LAS TINIEBLAS}

Estamos totalmente inmersos en la nueva era del 'Dark Enlightenment', argumenta "Bifo" Berardi (2019), o la New Dark Age, como la denomina Bridle (2018). "Nadie decidió que así es como debería evolucionar el mundo, nadie quería la New Dark Age, pero la construimos de todos modos, y ahora vamos a tener que vivir en ella". Lo que nos espera es un futuro colapsado que "es más viejo y más vasto que nuestro presente", donde la razón y la vida se someten a la ferocidad de las matemáticas financieras, los algoritmos y la tecnología en el cuál nosotros somos los ‘alienígenas' de Le Guin (2018). A pesar de esta oscuridad que nos engulle cual agujero negro, nuestra actitud consiste en no asumir ninguna responsabilidad. Lo que me hace pensar el término de la poética aristotélica, hamartia. No merecíamos la caída, buscábamos que nos compadecieran pero, en última instancia, somos los únicos responsables porque hemos fallado el tiro, ahora solo nos queda ejercer la catarsis hacia un futuro transhumanista donde STEAM nos educará con la misma lógica que nos ha llevado al desastre. Ya que, como argumenta Virilio (2012), "promover el progreso significa que siempre estamos detrás: del Internet de alta velocidad, de nuestro perfil de Facebook, de nuestra bandeja de entrada de correo electrónico. Siempre hay actualizaciones que hacer; Somos los objetos del 
masoquismo diario y estamos bajo tensión constante". Hemos normalizado un proceso que nada tiene de ordinario ni de accidente.

Los humanos, más que reliquias, quedaremos reducidos a tecno-escombros. El futuro no nos necesita. Un futuro, no tan lejano, donde las máquinas serán entes espirituales de salvación y condena, que están siendo creadas y alimentadas a golpe de usuario. Como la distopía cyberpunk del anime Psycho-Pass (2012), donde un simple escaneo puede determinar nuestro estado mental, personalidad y la probabilidad de que vayamos a cometer delitos, así como nuestro destino y función en la sociedad. Puede sonar a cacotopía trasnochada pero cada día parece más real, estamos inmersos en un episodio de Black Mirror creado por todos nosotros.

El éxito (económico) es lo único que posee valor, ya que "el principio de intercambio comercial es el único principio ético racional". No es de extrañar que los libros de Rand sean referencia para los grandes de Silicon Valley, aunque ahora haya algunos que renieguen de su participación al ver las consecuencias de sus actos. El egoísmo, por muy racional que sea, sigue siendo igual de voraz. Orwell (1941) nos avisaba del "intento del Estado moderno de controlar la vida emocional del individuo", la actualización de esta frase sería el cambio del sujeto estado por el sujeto económico; la intención sigue siendo la misma, el controlador es lo único que cambia. La mercantilización de la afectividad humana nos lleva a proclamas como la de Rand (2009), "sólo por los deseos, las emociones, las aspiraciones, los sentimientos, los caprichos o las necesidades de brutos irracionales que jamás lograron superar la práctica primitiva de los sacrificios humanos, que nunca descubrieron una sociedad industrial y que no conciben otro interés personal que el de arrebatar el botín del momento".

Esta nueva era de las tinieblas tiene uno de sus mayores aliados en la post-verdad. Peter Pomerantsev (2016) argumentaba en su artículo Why we're Postfact que "los nuevos medios, con sus innumerables pantallas y transmisiones, hacen que la realidad está tan fragmentada que se vuelve indescifrable, empujándonos o permitiéndonos huir hacia realidades y fantasías virtuales. La fragmentación, combinada con las desorientaciones de la globalización, deja a las personas anhelando un pasado más seguro, generando nostalgia”. La realidad como concepto fraccionado y sujeto a narrativas condicionadas por la lógica del capital, la política y la tecnología confirma la hipótesis de que STEAM no es más que una versión estetizada del entrepreneur, figura estrella de las tinieblas. La educación no tiene ánimo de lucro, es un derecho y no un privilegio. 
Hay un problema ético de base que no se soluciona con añadir el arte para pseudo humanizarlo, así como la historia ya no puede ser entendida en términos de narración sino que ha tomado la forma de un 'huracán semiótico', como así lo define "Bifo" Berardi (2019). Nuestra historia actual está en las tinieblas.

\section{ESCOMBRO DE ANTROPOCENO}

Estamos destinados a acabar como escombro de Antropoceno, puro residuo del "capitalismo industrial, donde el cálculo prevalece como criterio de toma de decisiones; como tal, esto constituye el advenimiento del nihilismo", cómo lo define Stiegler (2018). Las tinieblas siguen al acecho y no les estamos prestando ninguna atención. Una desatención cortés que desvía la mirada y cualquier interacción para ocultar nuestra verdadera identidad e intencionalidad. Este concepto fue definido por Goffman (1959) y aún sigue vigente. Se ha convertido en algo innato en todos nosotros. Puro desdén con aquellos que no siguen el ritmo, ya que el desprecio ya no está reservado a los excluidos o a los invisibles sino que se expande, como argumenta Sloterdijk (2002), al "mundo moderno, un lugar de enfrentamiento de luchas generalizadas por el reconocimiento, donde el desprecio alcanza cotas epidémicas". La desatención es una consecuencia más de nuestra pasividad enmascarada.

El Antropoceno es un hyperobject. El concepto de hyperobjeto está definido por Morton (2014) como "algo que nos rodea, nos envuelve y nos enreda", cuya influencia se percibe más allá de su comprensión total. Internet, la Covid19 , el cambio climático... también lo son. Nos afectan pero pueden existir sin nosotros. Cada vez que mandamos gifs animados a los grupos de WhatsApp, sobrecargamos la CPU de nuestros dispositivos y recalentamos los centros de datos que los alojan, aunque solo notemos el molesto ventilador de nuestro portátil o un calorcillo en nuestros dispositivos móviles. Numerosos actos, a veces inconscientes, como usuarios van sumando un coste que va más allá de lo económico y alimentan día día un agujero negro. "La tecnología no surge de un vacio", dice Bridle (2018) y "ha aprendido a guardar sus secretos" mientras que nosotros los exponemos a diario alimentando a estos gigantes invisibles. Ya no hay vuelta atrás, "no podemos rechazar la tecnología contemporánea más de lo que podemos rechazar en última instancia y completamente a nuestros vecinos en la sociedad y el mundo: todos estamos conectados". La nueva 
era de las tinieblas está llena de hyperobjetos que se escapan a nuestro control, la tecnología ha sido la herramienta que lo ha permitido.

Después de la electrocución tecnológica hacia el apoteosis digital vendrá la parálisis; donde un imaginario deshidratado, no tendrá más opción que estallar en mil pedazos. El escombro que quede se conservará, estudiará y analizará hasta la extenuación quedará reducido a una versión estetizada lista para un consumo y digestión rápida con la aplicación oportuna . La llegada de los ordenadores personales a finales de los 70 prometía que serían "portadores de información, gestores del destino (el futuro está en los datos) y emancipadores" y, su uso estaría centrado en "el oficio, el juego y la producción". La argumentación de Johansson (1997) es bastante acertada pero no nos ha emancipado como prometió, ya que como indica Cuboniks (2018), ese potencial "sigue sin cumplirse". La tecnología solo tiene la intención de garantizar gadgets cuya vida útil se rige por el absolutismo de la obsolescencia programada, generando basura y reliquias de Antropoceno.

Según Stiegler (2018), una vez superada la toxicidad, llegará el Neganthropocene. Donde la acumulación del valor ya no será una prioridad. Una mirada al futuro, quizás, demasiado optimista. Antes de poder llegar al Neganthropocene tendremos que sobrevivir a las tinieblas.

\section{SUPERVIVENCIA Y MURMULLO EN LA ERA DIGITAL}

Hoover (2016) nos habla de sus padres como "inmigrantes digitales, nacidos antes de la adopción generalizada de la tecnología digital", mientras que él se considera un 'nativo digital', al haber crecido con ordenadores e internet. Pero existe otra generación, en la que yo me incluyo, que podría considerarse como supervivientes digitales. Una generación que ha crecido en el proceso de normalización y evolución de la tecnología digital, incluyendo el limbo creado entre lo analógico y lo digital, y el pre/post internet. Más que inmigrantes nuestra postura es de atrincherados. Estamos acostumbrados al cambio, a la adaptación. Durante décadas los formatos desaparecían a la misma velocidad en que eran creados. No existe nostalgia, no sé da por sentado la tecnología; los estándares cambian, nosotros también. Una supervivencia desde las trinche- 
ras $\sin f e$ infinita en la tecnocracia. La tecnología es una herramienta, no un ente omnipotente.

Nos encontramos en la era postfordista donde sistema de producción flexible precede a la producción industrial en serie creada por Henry Ford (fordismo) antes de la Primera Guerra Mundial. Una era donde la naturaleza humana se ha convertido en una apuesta económica. El arte no se ha librado de esta lógica y se ha vuelto flexible y murmurador. Para entender esta reflexión introducimos el concepto del 'murmullo' como "una polifonía de singularidades y significados idiosincrásicos", donde los significados paradójicos se combinan y se contradicen entre sí. Esta hipótesis está planteada por Gielen (2015) y se basa en el libro Grammar of the multitude de Paolo Virno. Un arte flexible en el que el virtuosismo ha pasado de ser una destreza a la capacidad de los artistas para legitimizarse a través de la ejecución verbal de sus ideas. Según Gielen (2015), la multitud artística actual depende de las ayudas, subsidios y demás fórmulas económicas procedentes de los gobiernos e instituciones público / privadas, al menos en Europa, creando una dependencia que permite al artista sumergirse aún más en la singularidad, y así ser absorbido. Una 'multitud murmuradora' que, como argumenta San Martín (2019), "fuera del espectáculo, todo arte parece críptico a los ojos del apresurado y pasivo espectador. Y precisamente críptico es uno de los adjetivos que más se identifica con el arte contemporáneo, una disciplina hermética solo apta para especialistas".

Las palabras del lujo son una práctica bastante extendida entre los artistas, un estándar en la legitimación de la producción así como su valor económico y estatus. A estos artistas que murmullan lo único que interesa es el reflejo de su propia existencia y práctica. Podríamos estandarizar como crítico artístico al algoritmo psicoterapéutico ELIZA creado por Joseph Weizenbaum en la década de los setenta que reformulaba las frases escritas por el usuario, en este caso el artista, a modo de pregunta o reflexión dando la impresión de total entendimiento. Una metáfora de la computabilidad como espejo ya que, como dijo Sartre (1940), "no queremos saber nada de la imagen, solamente lo que reflejo nos puede enseñar".

La "banalidad y la indigencia intelectual" del público que critica San Martín (2019) es consecuencia de la arrogancia de la élite artística. En el libro Digital folklore, Lialina y Espenschied (2009) nos preguntaban si creíamos en los usuarios y en la cultura digital amateur, ya que su plan era, "restablecer una relación razonable entre las computadoras y las personas". No debemos olvidar que la tecnología ha democratizado el arte, forjando y destronando nuevas 
élites; así como generando movimientos alternativos y artistas más allá de la academia, la universidad, las galerías y los museos. El concepto clave aquí es usar. Mientras sigan existiendo usuarios, la tecnología antigua o no, seguirá su camino más allá de su propósito mercantil. La soberbia en el arte tiene mucho que aprender de la honestidad de la cultura digital amateur. Sin ella se habría quedado desfasada.

No hay nadie que se libre de paradojas pero las palabras están exhaustas y, peor aún, están siendo lanzadas contra la pared. Algunas explotan, desaparecen, mutan o caen a la fosa común del exceso. Se manosean y se destruye sin pudor su sentido, ajustándolo a la narrativa que más convenga, sobre todo a la política y la corporativa; pero el arte tampoco se queda atrás. Nadie quiere hacerse cargo, nadie asume ningún tipo responsabilidad porque este proceso se ha normalizado, es otro estándar de consumismo masivo. Tal atropello está impacientando su venganza y ya poco podemos fiarnos de ellas y acabarán por rebelarse contra nosotros. La postmodernidad se dedicó a promover y glorificar el todo vale y la tecnología lo hizo factible. Toda aquella argumentación teórica ha acabado aislándonos en islas como las de Ballard (1974), "hay otras islas que están mucho más cerca de casa, algunas de ellas solo a unos pocos pasos de las aceras que transitamos cada día. No están rodeadas de mar, sino de hormigón, circundadas por verjas de alambre y paredes de cristal a prueba de bombas [...] La tecnología moderna ofrece una inagotable vía de escape para ese lado desviado de nuestra personalidad. Abandonados en un edificio de oficinas o entre dos terraplenes en medio de una autopista, podemos tiranizarnos a nosotros mismos, poner a prueba nuestras fuerzas y debilidades, quizá hasta llegar a un acuerdo con aspectos de nuestro carácter ante los que siempre hemos cerrado los ojos".

El arte murmurante se ha fagocitazo la certeza científica, matemática y económica. El abuso de las palabras ha llevado a los artistas hacia la seguridad de las ciencias, de tal forma que la falta de significado parece paliarse con pseudo procesos científicos que legitimizan y confirman la nueva era de las tinieblas (New Dark Age) como un mero añadido estético producto de la narrativa económica. Aunque incluso de los murmullos surjan "nuevos idiomas, proliferando en todo el mundo, mutando a nuevas formas y desvaneciéndose en la obsolescencia", como argumenta Hayles (2005); solo dejarán a su paso reliquias y escombros para el futuro. 


\section{CONCLUSIÓN}

La era digital ha dado paso a la era de las tinieblas. Las monumentos conmemorativos ya no se construyen fisicamente sino únicamente sus narrativas. STEAM es uno de estos monumentos. Un sistema educacional ligado a la prosperidad económica que utiliza la disciplina del arte como un contingente estético para introducir la sensibilidad en la lógica económica y tecnológica. Un ruido de fondo decorativo que producirá souvenirs, archivos online y basura almacenada. Más que murmullo, el arte será otro escombro más del Antropoceno. Lo que se cuestiona no es la relevancia de las disciplinas sino la conexión con la figura del entrepreneur. Las humanidades no forman parte de las disciplinas de STEAM, lo que confirma que la elección del arte no es aleatoria.

No se busca su espíritu crítico ni su sensibilidad, sino su capacidad flexible y murmurante capaz de adaptarse y sumirse a la certeza científica, matemática, económica y tecnológica, al 'Techno-Totalitarian Reich', a la teocracia del algoritmo. No busca el bien común, ni llevarnos al Negantropoceno; sino la creación reliquias y escombros para el futuro, a la Ruinenwert acelerada. No hay un replanteamiento ético más allá del lucro, solo la promesa de un post-futuro que sigue estancado en el pasado. Un tecno-medievo sin manual de instrucciones pero con conexión a internet. ¿Qué más queremos? En nuestra manos está aprovechar el tiempo que se nos ha dado. No caben más excusas. Aún podemos resistirnos.

\section{Referencias bibliográficas}

Avanessian, Armen \& Mauro Reis, eds. 2017. Aceleracionismo: Estrategias para una transición hacia el postcapitalismo. Franco 'Bifo' Berardi et al.; traducción, Mauro Reis. Buenos Aires: Caja Negra

Ballard, James Graham. (1974) 2012. La isla de hormigón. Traducción de Manuel Manzano. Barcelona: RBA

Berardi, Franco ['Bifo']. 2019a. Breathing: Chaos and poetry. Los Angeles CA: Semiotext(e)

Berardi, Franco ['Bifo']. 2019b. "(Sensitive) consciousness and time: Against the transhumanist utopia”. E-Flux 98. https://www.e-flux.com/journal/98/257322/sensitive-consciousness-and-time-against-the-transhumanist-utopia/

Bridle, James. 2018. New dark age: Technology, knowledge and the end of the future. London: Verso

Finn, Ed. 2018. La búsqueda del algoritmo: Imaginación en la era de la informática. Traducción de Héctor Castells Albareda. Barcelona: Alpha Decay 
Gielen, Pascal. 2015. The murmuring of the artistic multitude: Global art, politics and Post-Fordism. Translation, Clare McGregor. Amsterdam: Valiz

Goffman, Erving. (1956) 2012. La presentación de la persona en la vida cotidiana. Traducción, Hildegarde B. Torres Perrén \& Flora Setaro. Buenos Aires: Amorrortu

Hayles, Katherine N. (2005) 2010. My mother was a computer: Digital subjects and literary texts. Chicago: University of Chicago

Hoover, Ryan. 2016. "Artificial intelligence natives". Medium.com, Oct. 16. https://medium. com/@rrhoover/artificial-intelligence-natives-10a9843aa9a1

Johansson, Magnus. 1997. Smart, fast and beautiful: on rhetoric of technology and computing discourse in Sweden 1955-1995. Linköping: Linköping University

Laboria Cuboniks. 2018. The xenofeminist manifesto: A politics for alienation. London: Verso

Le Guin, Ursula K. (1974) 2018. Los desposeídos. Traducción de Matilde Horne. Barcelona: Minotauro

Le Guin, Ursula K. 2018. Contar es escuchar: Sobre la escritura, la lectura, la imaginación. Martín Schifino, traductor. Madrid: Círculo de Tiza

Lialina, Olia \& Dragan Espenschied, eds. 2009. Digital folklore: To computer users, with love and respect. Designed by Manuel Buerger. Stuttgart: Merz \& Solitude

Morton, Timothy. 2014. Hyperobjects: philosophy and ecology after the end of the world. Minneapolis MN: University of Minnesota

Orwell, George et al. 2017. El poder y la palabra: 10 ensayos sobre lenguaje, política y verdad. Miquel Berga i Bagué, ed.; Inga Pellisa Díaz, trad. Barcelona: Debate

Pomerantsev, Peter. 2016. "Why we're post-fact". Granta.com, July 20. https://granta.com/whywere-post-fact/

Rand, Aynb. (1961) 2009. La virtud del egoísmo: Un nuevo y desafiante concepto del egoísmo. Traducción, Luis Kofman. Buenos Aires: Grito Sagrado

San Martín Martínez, Francisco Javier. 2019. Guía para el arte del siglo XXI. Bilbao: BilbaoArte

Sartre, Jean-Paul. (1940) 2004. Imaginary: A phenomenological psychology of the imagination. Revisions and historical introduction by Arlette Elkaïm-Sartre; translated and philosophical introduction by Jonathan Webber. London: Routledge

Sloterdijk, Peter. 2002. El desprecio de las masas: Ensayo sobre las luchas culturales de la sociedad moderna. Traducción de Germán Cano. Valencia: Pre-Textos

Sterling, Bruce. 2009. "The Fascist theory of ruin value". Wired.com, Nov. 13. https://www.wired. com/2009/11/the-fascist-theory-of-ruin-value/

Stiegler, Bernard. 2018. The Neganthropocene. London: Open Humanities

Virilio, Paul. 2012. The administration of fear. With Bertrand Richard; translated by Ames Hodges. Los Angeles CA: Semiotext(e) 